\title{
Sporulation of Clostridium cellulolyticum while Grown in Cellulose-Batch and Cellulose-Fed Continuous Cultures on a Mineral-Salt Based Medium
}

\author{
M. Desvaux, H. Petitdemange \\ Laboratoire de Biochimie des Bactéries Gram +, Domaine Scientifique Victor Grignard, Université Henri \\ Poincaré, Faculté des Sciences, BP 239, 54506 Vandœuvre-lès-Nancy Cédex, France
}

Received: 1 October 2001; Accepted: 26 November 2001; Online publication: 24 January 2002

\section{A}

Clostridium cellulolyticum sporulation was investigated during growth on cellulose fibers in a mineral-salt based medium which corresponds to conditions linked to its natural ecological niche. At steady state of the continuous cultures under limitation and with an excess of cellulose and/or ammonium, bacterial cells mainly sporulated at low dilution rates $(D)$, at least $10 \%$ sporulation being observed at the lowest $D$ tested. Increasing the cellulose concentration in the feed-medium reservoir increased the percentage of spores in the bioreactor. It appeared that the remaining undigested cellulose could serve as an exogenous carbon source supply at a continuous but limited rate throughout the sporulation process. In addition to the proportion of carbon and nitrogen, the influence of the environmental $\mathrm{pH}$ on spore formation was studied. In cellulose-fed continuous cultures at a constant $D$ and a $\mathrm{pH}$ decreasing from 7.2 to 6.4 , the percentage of spores increased to $14 \%$ at the lowest $\mathrm{pH}$ tested. When C. cellulolyticum was grown in batch culture, the level of sporulation was dramatically higher in unregulated-pH fermentation compared to $\mathrm{pH}$-controlled growth conditions at $\mathrm{pH} 7.2$ since in the former it reached $45 \%$ within 5 days of cultivation. It then appeared that a low specific growth rate and a low environmental $\mathrm{pH}$ in the presence of an insoluble carbon substrate were the major factors inducing sporulation in C. cellulolyticum. Furthermore, since the spores adhere to the carbon substrate (the cellulose) the bacteria gain advantages when the environment allows germination thanks to the recovery of suitable growth conditions. By allowing the maintenance and the integrity of the bacteria in the microbiota, spore formation could then explain the successful survival of C. cellulolyticum in cellulosic anaerobic habitats where low environmental $\mathrm{pH}$ conditions are often found. 


\section{Introduction}

The ecology of cellulose degradation in anaerobic environments is closely linked to global carbon cycling in the biosphere [29]. Anaerobic environments rich in decaying plant material are prevalent and the final products of cellulose fermentation are methane and carbon dioxide [2, 43]. Bacteria are the major cellulose hydrolyzers in anaerobic cellulosic microbiota $[30,39]$ where cellulolytic clostridia play a key role [29].

Clostridium cellulolyticum, a nonruminal cellulolytic mesophilic bacterium isolated from decayed grass [35], enables digestion of cellulosic materials via extracellular multienzymatic complexes containing various cellulases organized around a scaffolding protein called CipC $[4,33]$. The cellulosomes allow both bacterial adhesion and efficient degradative activity against crystalline cellulose [3, 6], For the cellulose degradation process by $C$. cellulolyticum, which must be considered as a microbial process rather than a purely enzymatic event, an adhesion-colonization-release-readhesion model has been proposed $[21,22]$.

In this latter model, the long-term survival of the cellulolytic bacterium is assured by sporogenesis and germination following recovery of substrates [19]. Most of the cellulolytic clostridia isolated from various biotopes form spores $[5,40]$, but admittedly considerable variation in the environmental conditions triggering sporulation in clostridia has been found $[37,44]$. Recently it was shown that C. cellulolyticum sporulation was mainly related to the dilution rate and followed a down-up-down sporulation pattern as specific growth rates increased [34].

Most of the first investigations carried out with $C$. cellulolyticum were performed on complex media with cellobiose, a soluble cellodextrin, which countered the continuous cultivation of the bacterium on cellulose as sole carbon and energy source. Later investigations demonstrated that growth of $C$. cellulolyticum in a complex medium [25] and/or with an easily available soluble carbon source $[12,14,15]$ resulted in metabolic deregulations, pointing out that these growth conditions did not properly represent the natural ecosystem of the bacterium.

Continuous culture is a method of choice to analyze bacterial metabolism, and in the past decade, efficient continuous culture devices for growth on insoluble compounds have been developed [41]. In natural environments, growth conditions most likely resemble those of an open continuous-culture system or at least somewhere between an open system and a closed batch culture [28]. By using both types of culture system, the aim of the present study was to investigate the sporulation of $C$. cellulolyticum when grown in a mineral-salt based medium with cellulose, which are growth conditions closely linked to its natural environment.

\section{Methods}

\section{Organism and Medium}

Clostridium cellulolyticum ATCC 35319 was isolated from decayed grass [35]. Stocks of spores, stored at $4^{\circ} \mathrm{C}$, were transferred to cellulose medium and heat shocked at $80^{\circ} \mathrm{C}$ for $10 \mathrm{~min}$ [12]. Anaerobic cell cultures were subcultured once on cellulose before inoculation and growth in the bioreactor [12]. The defined medium used in all experiments was a modified CM3 medium [24] containing various amounts of cellulose MN301 (Macherey-Nagel, Düren, Germany) and ammonium as specified in the Results section.

\section{Growth Conditions}

Clostridium cellulolyticum was grown on cellulose as sole carbon and energy source and ammonium as nitrogen source using a mineral salt based medium. All experiments were performed in a $1.5 \mathrm{~L}$ working volume fermentor (LSL Biolafitte, St. Germain en Laye, France). The temperature was maintained at $34^{\circ} \mathrm{C}$ and the $\mathrm{pH}$ was controlled by automatic addition of $3 \mathrm{M} \mathrm{NaOH}$ or $1 \mathrm{M}$ $\mathrm{HCl}$. The inoculum was $10 \%$ by volume from an exponentially growing culture.

Batch culture with cellulose was performed as previously described [12, 13], and the cellulose-fed continued-culture was a segmented gas-liquid continuous-culture device as described by Weimer et al. [41] with some modifications [14]. Each continuous-culture run was independent and performed as previously described [13-16]. Once steady state of the continuous culture was reached, culture samples were removed at 6 to 30 -h intervals and for each condition the data were the average from at least 3 samples collected over 2- to 8-day periods [14].

\section{Analytical Procedures}

Biomass was estimated by bacterial protein measurement [12].

The percentage of spores versus total cells was estimated by counting using an epifluorescence microscope as previously described [34].

Culture supernatants $\left(10,000 \times \mathrm{g}, 15 \mathrm{~min}, 4^{\circ} \mathrm{C}\right)$ were stored at $-80^{\circ} \mathrm{C}$ until analysis.

Ammonium was assayed by the method of Chancy and Marbach [8].

Cellulose concentration was determined as described [12]. 


\section{Results}

Clostridium cellulolyticum Sporulation with Increasing

Concentrations of Ammonium and Cellulose

With increasing concentration of cellulose in the feed medium from 1.9 to $27.0 \mathrm{~g} \mathrm{~L}^{-1}$ and $15.13 \mathrm{mM}$ of ammonium, continuous cultures were performed at a dilution rate of $0.048 \mathrm{~h}^{-1}$ in independent runs (Fig. 1a). Above $7.6 \mathrm{~g} \mathrm{~L}^{-1}$ of cellulose, the biomass at steady state leveled off at $296 \mathrm{mg} \mathrm{L}^{-1}$. In contrast, the percentage of cellulose degradation declined from 32.3 to $8.3 \%$ as the amount of cellulose input was increased (Fig. 1a). Cellulose digestion was not complete at any of the cellulose concentrations tested but the production of biomass paralleled the amount of consumed cellulose $[12,15]$. As for the sporulation efficiency, it increased as the cellulose concentration was increased to reach $8 \%$ at the highest cellulose concentration tested (Fig. 1a). At a dilution rate of $0.048 \mathrm{~h}^{-1}$ with $18.1 \mathrm{~g} \mathrm{~L}^{-1}$ of cellulose MN301 and with increasing concentrations of ammonium from 2.27 to $30.27 \mathrm{mM}$, biomass leveled off at $305 \mathrm{mg} \mathrm{L}^{-1}$ above 8.10 $\mathrm{mM}$ of ammonium input (Fig. 1b). Thus the stagnation of biomass formation could not be related to starvation for either cellulose or ammonium, or for other nutrient(s) since cell density was not modified when the amount of all other components of the medium was increased [16]. As
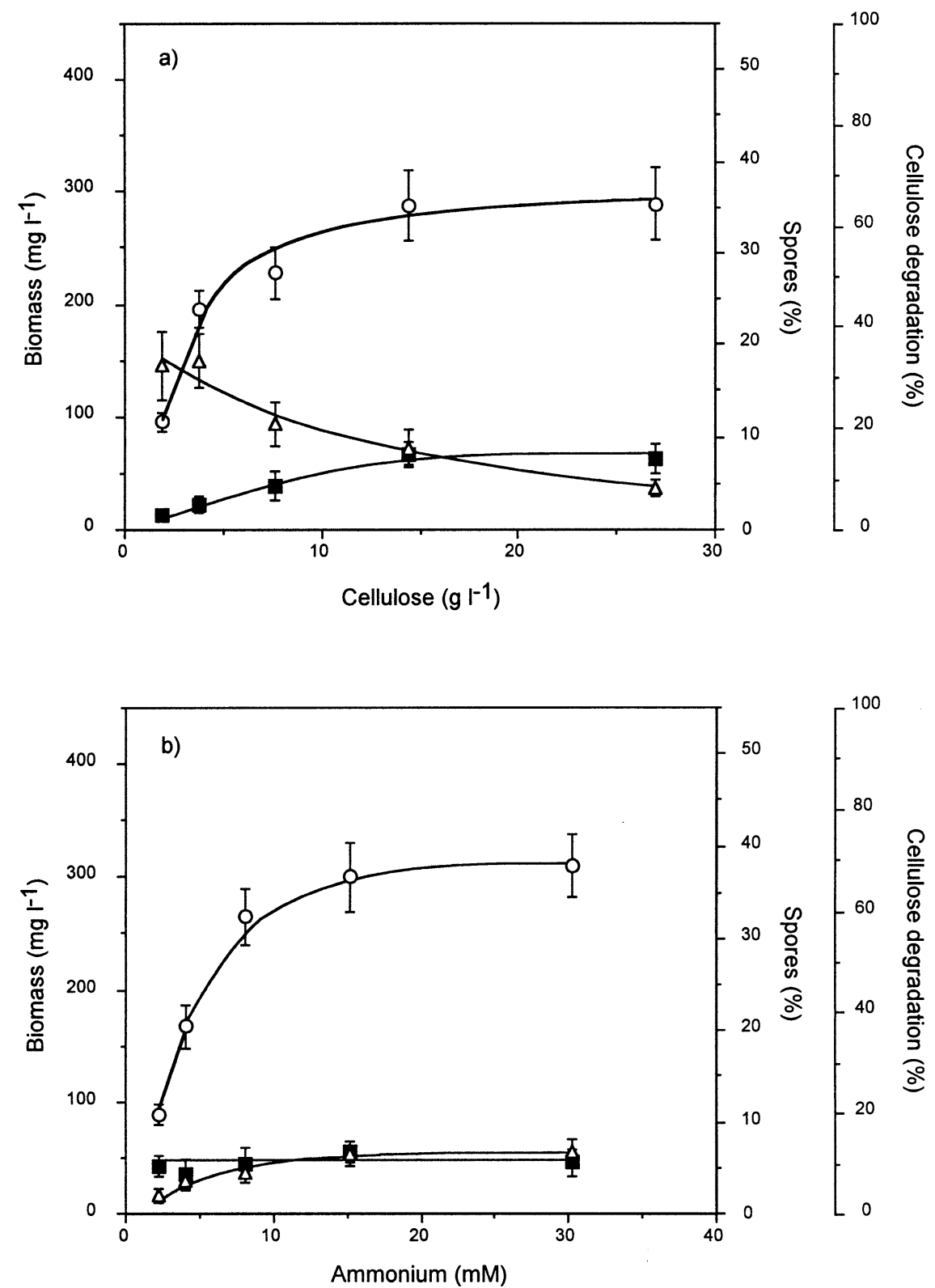

Fig. 1. Influence of increasing concentrations of carbon and nitrogen source on sporulation of $C$. cellulolyticum. Bacteria were grown in continuous culture at $D=0.048 \mathrm{~h}^{-1}$ with (a) various amounts of cellulose while ammonium was in excess, i.e., $15.13 \mathrm{mM}$, or (b) ammonium while cellulose was in excess, i.e., $18.1 \mathrm{~g} \mathrm{~L}^{-1}$ (b). $\odot$, biomass; $\Delta$, percentage of cellulose degradation; $\boldsymbol{\square}$, percentage of sporulation. 
the ammonium concentration in the feed reservoir was increased, the percentage of cellulose degradation increased as well to reach $12.1 \%$ with $30.27 \mathrm{mM}$ of ammonium and was correlated with the higher generated biomass (Fig. 1b). The percentage of sporulation, however, was not changed by the amount of ammonium input and remained around $5 \%$.

\section{Influence of Dilution Rate on Clostridium cellulolyticum Sporulation}

Cellulose-limited continuous cultures were carried out with $3.7 \mathrm{~g} \mathrm{~L}^{-1}$ of cellulose in the feed reservoir and dilution rates ranging from 0.027 to $0.083 \mathrm{~h}^{-1}$ (Fig. 2a) [14]. Maximum cell density was obtained at $D=0.027 \mathrm{~h}^{-1}$, i.e., $212 \mathrm{mg} \mathrm{L}^{-1}$, and slowly declined as $D$ rose to reach $154 \mathrm{mg} \mathrm{L}^{-1}$ at the highest $D$ tested. The highest percentage of cellulose degradation was obtained with the lowest $D$ tested, i.e., $50.4 \%$, and decreased with increasing growth rate to reach $20.9 \%$ at $0.083 \mathrm{~h}^{-1}$. Under these experimental conditions, cultures of $C$. cellulolyticum were observed to sporulate at low specific growth rates; a maximum percentage of spores of $11 \%$ was found at $D=0.027 \mathrm{~h}^{-1}$.

Nitrogen-limited chemostats with $4.00 \mathrm{mM}$ ammonium and with cellulose at saturated concentration $\left(18.1 \mathrm{~g} \mathrm{~L}^{-1}\right)$ were performed with dilution rates from 0.027 to $0.085 \mathrm{~h}^{-1}$ (Fig. 2b) [16]. The residual ammonium concentration was barely detectable at low specific growth rates $(<0.10 \mathrm{mM})$, but was $3.02 \mathrm{mM}$ with the highest $\mu$ tested. Such data are typical of continuous culture performed under limitation of a selected nutrient [47]. Under these experimental conditions, biomass at steady state ranged from 187 to $62 \mathrm{mg} \mathrm{L}^{-1}$ as $D$ rose while at the same time, the percentage of cellulose degradation ranged only from 9.5 to $1.8 \%$. As under cellulose limitation, the same sporulation pattern as a function of $D$ was observed; continuous cultures of $C$. cellulolyticum were observed to sporulate mainly at low dilution rates with a maximum percentage of sporulation of $10 \%$ found at $D=0.027 \mathrm{~h}^{-1}$.

With saturated concentrations of all nutrient including both ammonium $(15.13 \mathrm{mM})$ and cellulose $\left(18.1 \mathrm{~g} \mathrm{~L}^{-1}\right)$ in the feed reservoir, $C$. cellulolyticum was cultivated at various $D$ values (Fig. 2c) [15]. Cell density was higher than in cellulose- or ammonium-limited chemostats since it ranged from 367 to $161 \mathrm{mg} \mathrm{L}^{-1}$. As observed under limitation of ammonium or cellulose, the biomass concentration declined with $D$ but more sharply than in the previously tested culture conditions. With cellulose and ammonium saturation the proportion of digested cellulose was lower than in cellulose-limited condition since it ranged from 21.4 to $5.3 \%$ with increasing $D$. As previously observed, spore formation mainly occurred at low $D$ values; the percentage of sporulation was, however, consistently higher than in limited conditions since it ranged from 3 to $15 \%$ as $D$ declined.

\section{Influence of $\mathrm{pH}$ on Clostridium cellulolyticum Sporulation in Batch and Continuous Cultures}

Batch cellulose cultivations of $C$. cellulolyticum were performed with $6.7 \mathrm{~g} \mathrm{~L}^{-1}$ of cellulose under unregulated$\mathrm{pH}$ and $\mathrm{pH}$-stat conditions (Fig. 3) [12, 13]. Within 5 days, the maximum cell density was reached in batch cultures controlled at $\mathrm{pH} 7.2$ with $495 \mathrm{mg} \mathrm{L}^{-1}$ compared with $281 \mathrm{mg} \mathrm{L}^{-1}$ in unregulated $\mathrm{pH}$ fermentation, as was the percentage of cellulose digestion, which was $80.3 \%$ and $61.2 \%$ with and without $\mathrm{pH}$ regulation, respectively (Figs. $3 \mathrm{a}$ and $3 \mathrm{~b})$. Sporulation of $C$. cellulolyticum began after 50-60 h of culture once bacterial cells had entered the stationary phase. Contrary to the maximum dry weight of cells or the maximum percentage of cellulose degradation, the percentage of sporulation was dramatically higher in non-pH-controlled cultures, i.e., 45\% (Fig. 3b), than in pH-controlled batch cultivation, i.e., 7\% (Fig. 3a).

C. cellulolyticum was grown in continuous cultures under cellulose-limited conditions at $D=0.053 \mathrm{~h}^{-1}$ and $\mathrm{pH}$ values decreasing from 7.2 to 6.4 in independent runs (Fig. 4) [13]. At and below pH 6.2, a steady state could not be established since washout occurred. As the $\mathrm{pH}$ was lowered, the cell density at steady-state declined to $56 \mathrm{mg} \mathrm{L}^{-1}$ at $\mathrm{pH}$ 6.4. Similarly the percentage of cellulose digestion decreased with lower $\mathrm{pH}$ values to reach $7.3 \%$ at pH 6.4 (Fig. 4). Contrary to the downward trend observed for the biomass and cellulose degradation for more acidic cultures, the percentage of sporulation increased to reach $14 \%$ at the lowest $\mathrm{pH}$ tested.

\section{Discussion}

In contrast to the genus Bacillus, where the regulation of sporulation has been investigated on a molecular basis [18, 46], in clostridial-type bacteria spore formation has so far not attracted much interest, especially in cellulolytic Clostridia $[26,31,37,38,42,44,45]$. As already shown with Bacillus $[10,11]$, in continuous culture the fraction of 

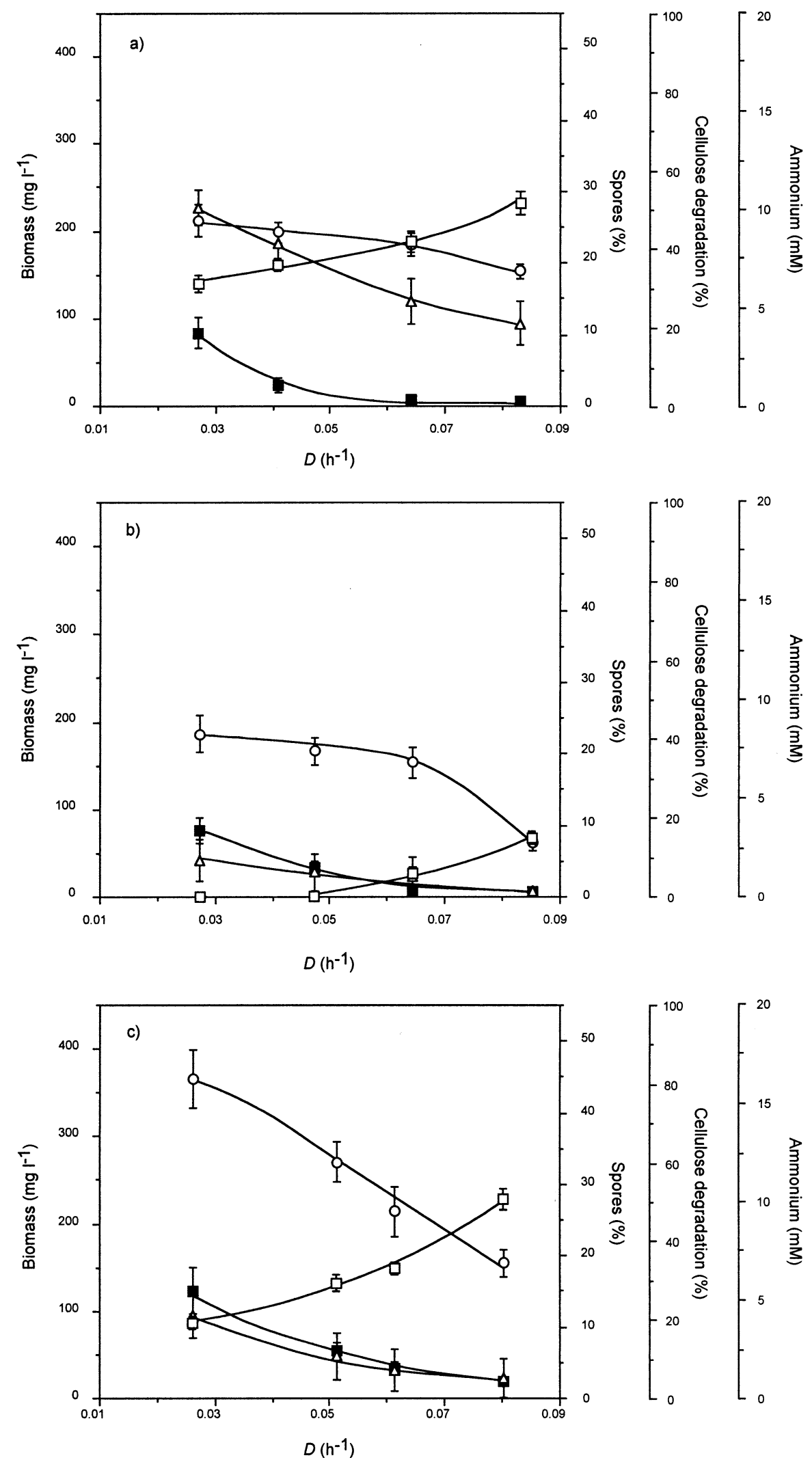

sporulated cells increases gradually with decreasing dilution rate. In natural environments the proportion of carbon and nitrogen can strongly influence cell growth and

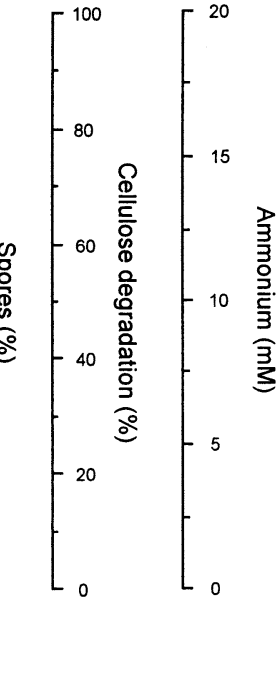

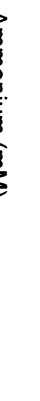

(1)

Fig. 2. Effect of dilution rate on spore formation by C. cellulolyticum. Cellulose-fed continuous cultures of $C$. cellulolyticum were performed (a) under cellulose limitation, i.e., $3.7 \mathrm{~g} \mathrm{~L}^{-1}$, (b) under ammonium limitation, i.e., $4.00 \mathrm{mM}$, and (c) under saturation of both cellulose and ammonium, i.e., $18.1 \mathrm{~g} \mathrm{~L}^{-1}$ and $15.13 \mathrm{mM}$, respectively. $\odot$, biomass; $\Delta$, percentage of cellulose degradation; $\mathbf{\square}$, percentage of sporulation; $\square$, ammonium. sporulation since these two compounds are major elements of microbial cell composition [1]. Furthermore, while cellulose accumulates in the environment because of 

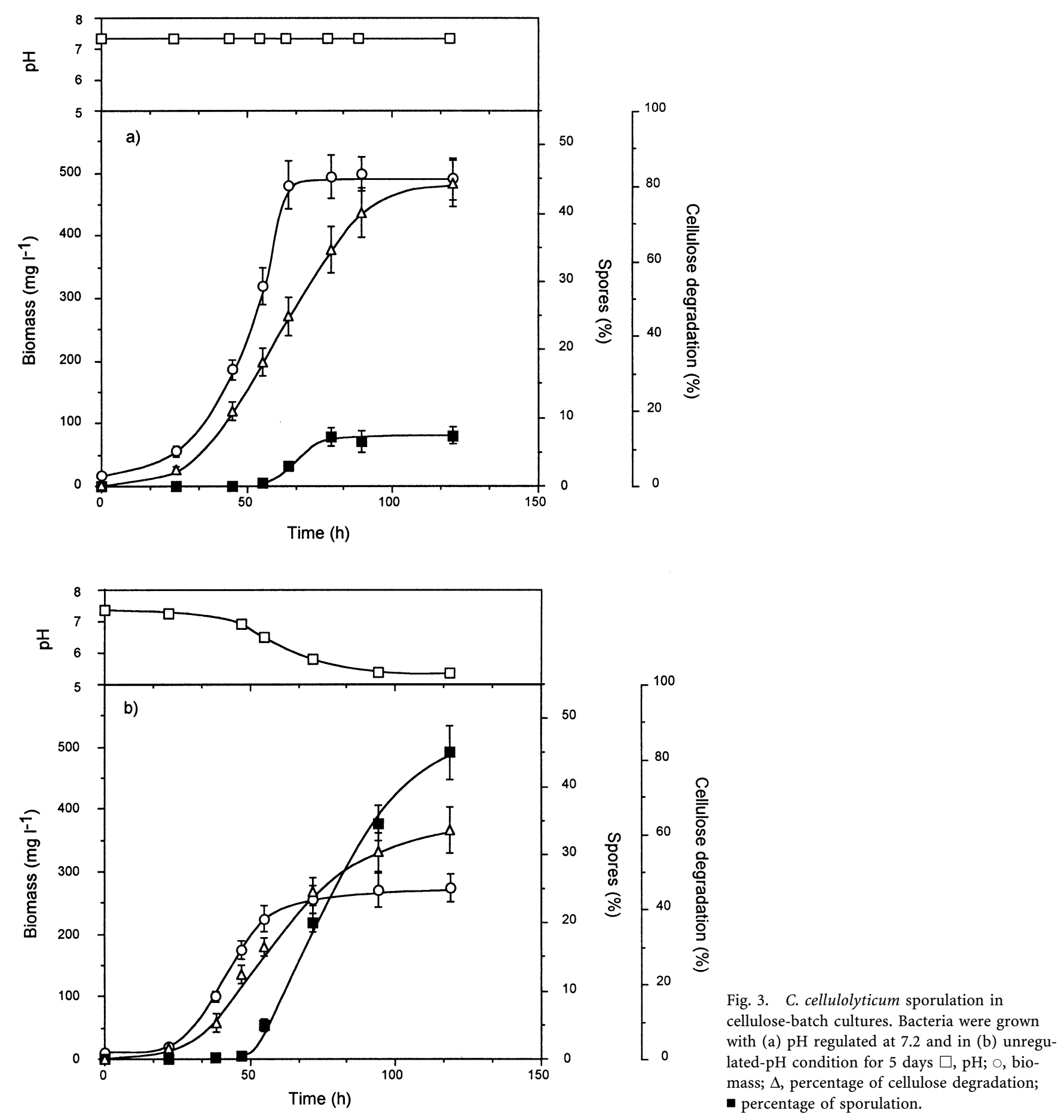

its recalcitrant, durable nature [2], lignocellulosic compounds usually contain a low level of nitrogen [16, 23]. In both cases of limitation and excess of ammonium and/or cellulose, sporulation efficiency was dependent upon growth rate.

From previous investigations with cellobiose limitation [34], C. cellulolyticum sporulation was maximal (12\%) at $D=0.035 \mathrm{~h}^{-1}$ and decreased at lower and higher $D$ values, i.e., $4 \%$ at $D=0.016 \mathrm{~h}^{-1}$ and $3 \%$ at $D=0.053 \mathrm{~h}^{-1}$ [34]. However, in the present study with insoluble cellulose, a similar down-up-down sporulation pattern as $D$ increased was not observed. Moreover, contrary to what was observed on cellobiose where an excess of soluble carbon substrate repressed spore formation [34], increasing cellulose concentrations promoted sporulation. These differences could be related to the physical nature of the 


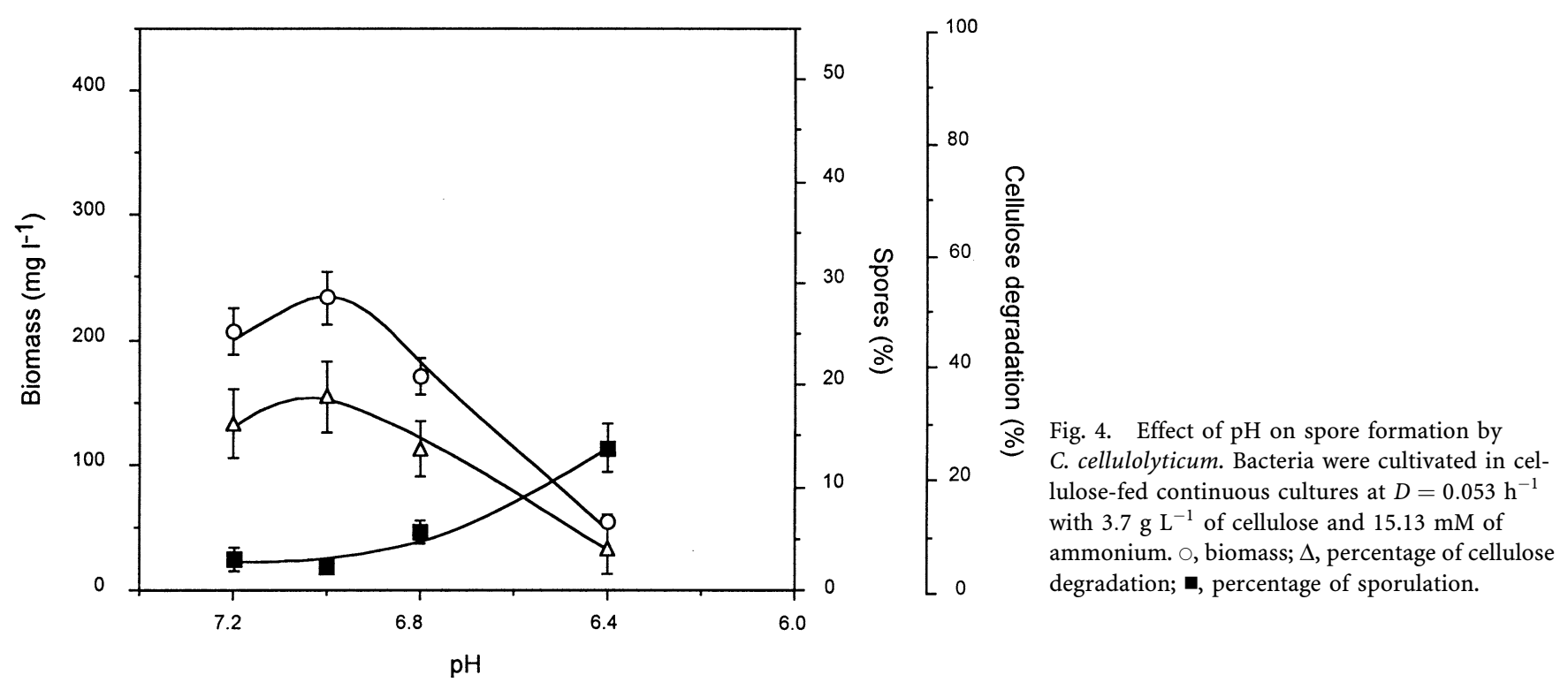

cellulose. Cell attachment could potentially modulate and trigger a particular physiological regulation [27] and the remaining cellulose could serve as an exogeneous energy source for sporulation by feeding bacterial cells continuously at a limited rate. This could be comparable to culture of $C$. thermosaccharolyticum where continuous and limited feeding of glucose, once the original carbon source was completely exhausted from the batch culture, allowed cell sporulation [26].

Quorum sensing could not be excluded as an explanation of some variations of the percentage of sporulation observed in different growth conditions [17]. In fact, at steady state with an excess cellulose concentration, cell density was lower in ammonium limitation than in ammonium excess, resulting in different percentages of sporulation at the same $D$. Similarly, when growth of $C$. cellulolyticum was studied as a function of $D$ under cellobiose limitation, the biomass concentration decreased as $D$ was lowered from 0.085 to $0.016 \mathrm{~h}^{-1}$ [26] while, in the same conditions on cellulose, the cell density at steady state increased [14], resulting in different percentages of sporulation, especially at low $D$ values where the difference of biomass concentration was greater between these two carbon substrates [34].

The growth of $C$. cellulolyticum on a complex medium and on a mineral salt-based medium resulted in different metabolic regulation and sporulation rates [24, 25, 34]. Also, the use of an easily available carbon source, such as cellobiose, compared to substrates more closely related to natural lignocellulosic compounds, such as cellulose, was shown to induce deregulation of $C$. cellulolyticum meta- bolism $[14,15,25]$ and discrepencies in the percentage of sporulation attributed to growth conditions far from the natural ecosystem of the bacteria. It should thus be noticed that the use of nitrogen sources different from ammonium could induce a particular metabolic regulation and a variation of sporulation efficiency [16]. In C. cellulolyticum, no correlation between glycogen accumulation and endospore formation was detected [34]. Glycogen is of key importance in $C$. cellulolyticum metabolism since it actively participates in the regulation of the carbon flow $[16,23]$. With C. acetobutylicum, Meinecke et al. obtained a stable asporogeneous mutant strain only after 35 days of chemostat culture at $D=0.125 \mathrm{~h}^{-1}$ [31]. Yet sporulation was not directly assayed since a correlation between the presence of spores and the presence of glycogen in colonies was used. Therefore, the asporogeneous strain was in the first instant aglycogenic. Such results point out that the influence of the carbon flow on sporulation and the importance of glycogen seem different in C. cellulolyticum and C. acetobutylicum.

Previous investigations [34] missed the possible influence of $\mathrm{pH}$ on sporogenesis in Clostridia [44, 45]. Anaerobic habitats are characterised by low $\mathrm{pH}$ conditions resulting from high concentrations of fermentation acids [30]. Clostridial-type bacteria are often considered to be sensitive to a low $\mathrm{pH}$ and restricted to less acidic ecological niches [36]. Culture of C. cellulolyticum under unregulated $\mathrm{pH}$ conditions was shown to be detrimental for optimum cellulose fermentation [13] which then affected spore formation. In continuous culture, as the $\mathrm{pH}$ declined, the cells sporulated and steady-state conditions 
could not be attained with a $\mathrm{pH}$ lower than 6.2. In unregulated-pH batch culture, sporulation of C. cellulolyticum was high and associated with the entry into the stationary phase. Spore formation can partially explain the arrest of metabolite production, previously observed in unregulated-pH conditions [13]. Spore formation then appeared as a process allowing the maintenance and the integrity of the cell mainly in response to an environmental $\mathrm{pH}$ decline rather than exhaustion of carbon substrate as previously assumed [20-22, 34, 42].

Adhesion and detachment to cellulose fibers are important factors in the behavior and physiology of C. cellulolyticum, which could also have regulatory function(s) $[2,20]$. While vegetative bacteria adhered to cellulose at specific sites [21], the adhesion of spores occurred by hydrophobic interactions and was thus a nonspecific process $[19,42]$. Sporulation of $C$. cellulolyticum while attached to lignocellulosic compounds allows successful survival and competition with other microorganisms since, as soon as environmental conditions permit it, cellulolytic bacteria can start a new vegetative cycle on a directly available carbon substrate, the cellulose fibers. For C. cellulolyticum, a low specific growth rate and mainly a low environmental $\mathrm{pH}$ in the presence of an insoluble carbon substrate were the major factors inducing sporulation. This study is a first step providing grounding for further investigation of the physiology and molecular biology of regulation of sporulation in C. cellulolyticum. Furthermore, understanding of the phenomena which allow favorable conditions for spore germination and thus cellulose degradation in the natural ecological niche requires that data from monospecies laboratory cultures must be extrapolated to microbiota where, as observed with the rumen microflora, complex interactions between cellulolytic and noncellulolytic microorganisms and environmental conditions take place $[7,9$, $32]$.

\section{Acknowledgments}

This work was supported by the Commission of European Communities FAIR program (Contract CT950191 [DG12SSMA]) and by the program Agrice (Contract 9701041). The authors thank Anne-Cécile Aubry and Guy Raval for excellent technical assistance and Edward McRae for correcting the English and for critical reading of the manuscript.

\section{References}

1. Aubert JP, Millet J, Schaeffer P (1965) Croissance et sporulation de Bacillus megaterium en culture continue. C R Acad Sci 261:2407-2409

2. Bayer EA, Lamed R (1992) The cellulose paradox: pollutant par excellence and/or a reclaimable natural resource? Biodegradation 3:171-188

3. Bayer EA, Chanzy H, Lamed R, Shoham Y (1998) Cellulose, cellulases and cellulosomes. Curr Opin Struct Biol 8:548-557

4. Belaich JP, Tardiff C, Belaich A, Gaudin C (1997) The cellulolytic system of Clostridium cellulolyticum. J Biotechnol 57:3-14

5. Benoit L, Cailliez C, Petitdemange E, Gitton J (1992) Isolation of cellulolytic Clostridia from a municipal solid waste digester. Microb Ecol 23:117-125

6. Boisset C, Chanzy H, Henrissat B, Lamed R, Shoham Y, Bayer EA (1999) Digestion of crystalline cellulose substrates by Clostridium thermocellum cellulosome: structural and morphological aspects. Biochem J 340:829-835

7. Cavedon K, Canale-Parola E (1992) Physiological interactions between a mesophilic cellulolytic Clostridium and a non-cellulolytic bacterium. FEMS Microbiol Ecol 86:237-245

8. Chaney AL, Marbach EP (1962) Modified reagents for determination of urea and ammonia. Clin Chem 8:130-132

9. Chen J, Weimer PJ (2001) Competition among three predominant ruminal cellulolytic bacteria in the absence or presence of non-cellulolytic bacteria. Microbiology 147:21-30

10. Dawes IW, Mandelstam J (1970) Sporulation in Bacillus subtilis in continuous culture. J Bacteriol 103:529-535

11. Dawes IW, Thornley JHM (1970) Sporulation in Bacillus subtilis: Theoretical and experimental studies in continuous culture systems. J Gen Microbiol 62:49-66

12. Desvaux M, Guedon E, Petitdemange H (2000) Cellulose catabolism by Clostridium cellulolyticum growing in batch culture on defined medium. Appl Environ Microbiol 66:2461-2470

13. Desvaux M, Guedon E, Petitdemange H (2001) Metabolic flux in cellulose batch and cellulose-fed continuous cultures of Clostridium cellulolyticum in response to acidic environment. Microbiology 147:1461-1471

14. Desvaux M, Guedon E, Petitdemange H (2001) Carbon flux distribution and kinetics of cellulose fermentation in steadystate continuous cultures of Clostridium cellulolyticum on a chemically defined medium. J Bacteriol 183:119-130

15. Desvaux M, Guedon E, Petitdemange H (2001) Kinetics and metabolism of cellulose degradation at high substrate concentrations in steady-state continuous cultures of Clostridium cellulolyticum on a chemically defined medium. Appl Environ Microbiol 67:3837-3845

16. Desvaux M, Petitdemange H (2001) Flux analysis of the metabolism of Clostridium cellulolyticum grown in cellulose-fed continuous culture on a chemically defined medium under ammonium-limited conditions. Appl Environ Microbiol 67:3846-3851 
17. Dunny GM, Winans SC (1999) Cell-Cell Signaling in Bacteria ASM Press, Washington, DC

18. Errington J (1993) Bacillus subtilis sporulation: regulation of gene expression and control of morphogenesis. Microbiol Rev 57:1-33

19. Gehin A, Gelhaye E, Petitdemange H (1996) Adhesion of Clostridium cellulolyticum spores to filter paper. J Appl Bacteriol 80:187-190

20. Gehin A, Gelhaye E, Raval G, Petitdemange H (1995) Clostridium cellulolyticum viability and sporulation under cellobiose starvation conditions. Appl Environ Microbiol 61:868-871

21. Gelhaye E, Gehin A, Petitdemange H (1993) Colonization of crystalline cellulose by Clostridium cellulolyticum ATCC 35319. Appl Environ Microbiol 59:3154-3156

22. Gelhaye E, Petitdemange H, Gay R (1993) Adhesion and growth rate of Clostridium cellulolyticum ATCC 35319 on crystalline cellulose. J Bacteriol 175:3452-3458

23. Guedon E, Desvaux M, Petitdemange H (2000) Kinetics analysis of Clostridium cellulolyticum carbohydrate metabolism: importance of glucose 1-phosphate and glucose 6phosphate branch points for distribution of carbon fluxes inside and outside cells as revealed by steady-state continuous culture. J Bacteriol 181:2010-2017

24. Guedon E, Desvaux M, Payot S, Petitdemange H (1999) Growth inhibition of Clostridium cellulolyticum by an inefficiently regulated carbon flow. Microbiology 145:18311838

25. Guedon E, Payot S, Desvaux M, Petitdemange H (1999) Carbon and electron flow in Clostridium cellulolyticum grown in chemostat culture on synthetic medium. J Bacteriol 181:3262-3269

26. Hsu EJ, Ordal ZJ (1969) Sporulation of Clostridium thermosaccharolyticum under conditions of restricted growth. J Bact 97:1511-1512

27. Jirku V (1997) Changes in the starvation response through covalent cell attachment. Antonie Leeuwenhoek 71:369-373

28. Kovárová-Kovar K, Egli T (1998) Growth kinetics of suspended microbial cells: from single-substrate-controlled growth to mixed-substrate kinetics. Microbiol Molecul Biol Rev 62:646-666

29. Leschine SB (1995) Cellulose degradation in anaerobic environments. Annu Rev Microbiol 49:399-426

30. Ljungdahl LG, Eriksson KE (1985) Ecology of microbial cellulose degradation. Adv Microb Ecol 8:237-299

31. Meinecke B, Bahl H, Gottschalk G (1984) Selection of an asporogeneous strain of Clostridium acetobutylicum in continuous culture under phosphate limitation. Appl Environ Microbiol 48:1064-1065

32. Morvan B, Rieu-Lesme F, Fonty G, Gouet P (1996) In vitro interactions between rumen $\mathrm{H}_{2}$-producing cellulolytic microorganisms and $\mathrm{H}_{2}$-utilizing acetogenic and sulfatereducing bacteria. Anaerobe 2:175-180

33. Pages S, Gal L, Belaich A, Gaudin C, Tardif C, Belaich JP (1997) Role of scaffolding protein CipC of Clostridium cellulolyticum in cellulose degradation. J Bacteriol 179:2810 $-2816$

34. Payot S, Guedon E, Desvaux M, Gelhaye E, Petitdemange E (1999) Effect of dilution rate, cellobiose and ammonium availabilities on Clostridium cellulolyticum sporulation. Appl Microbiol Biotechnol 52:670-674

35. Petitdemange E, Caillet F, Giallo J, Gaudin C (1984) Clostridium cellulolyticum sp nov, a cellulolytic mesophilic species from decayed grass. Int J Syst Bacteriol 34:155-159

36. Russell JB, Bond DR, Cook GM (1996) The fructose diphosphate/phosphate regulation of carbohydrate metabolism in low $\mathrm{G}+\mathrm{C}$ gram positive anaerobes. Res Microbiol 147:528-534

37. Sauer U, Santangelo JD, Treuner A, Buchholz M, Dürre P (1995) Sigma factor and sporulation genes in Clostridium. FEMS Microbiol Rev 17:331-340

38. Shih NJ, Labbé RG (1994) Effect of glucose on sporulation and extracellular amylase production by Clostridium perfringens type A in a defined medium. Curr Microbiol 29:163169

39. Tomme P, Warren RAJ, Gilkes NR (1995) Cellulose hydrolysis by bacteria and fungi. Adv Microb Physiol 37:1-81

40. Warshaw JE, Leschine SB, Canale-Parola E (1985) Anaerobic cellulolytic bacteria from wetwood of living trees. Appl Environ Microbiol 50:807-811

41. Weimer PJ, Shi Y, Odt CL (1991) A segmented gas/liquid delivery system for continuous culture of microorganisms on insoluble substrates and its use for growth of Ruminococcus flavefaciens on cellulose. Appl Microbiol Biotechnol 36:178-183

42. Wiegel J, Dykstra M (1984) Clostridium thermocellum: adhesion and sporulation while adhered to cellulose and hemicellulose. Appl Microbiol Biotechnol 20:59-65

43. Wolin MJ, Miller TL (1987) Bioconversion of organic carbon to $\mathrm{CH}_{4}$ and $\mathrm{CO}_{2}$. Geomicrobiol J 5:239-259

44. Woods DR, Jones DT (1986) Physiological responses of Bacteroides and Clostridium strains to environmental stress factors. Adv Microb Physiol 28:1-64

45. Wrigley DM, Hanwella HDSH, Thon BL (1995) Acid exposure enhances sporulation of certains strains of Clostridium perfringens. Anaerobe 1:263-267

46. Young M, Mandelstam J (1979) Early events during bacterial endospore formation. Adv Microb Physiol 20:103-162

47. Zeng AP (1999) Continuous culture. In: AL Demain and JE Davies (ed) Manual of Industrial Microbiology and Biotechnology. American Society for Microbiology, Washington, DC, pp 151-164 